\title{
Resenha crítica do livro: Faça acontecer - mulheres, trabalho e a vontade de liderar
}

\section{Critical review}

\author{
Ítalo de Paula Casemiro Mestre em Administração. Universidade Federal de Rondônia - Brasil. itcasemiro@hotmail.com \\ Natália Talita Araújo Nascimento Mestra em Administração Pública (Universidade Federal de Rondônia); e-mail: \\ natalia.araujo@unir.br
}

\section{REFERÊNCIA}

SANDBERG, Sheryl. Faça acontecer: mulheres, trabalho e a vontade de liderar. Tradução Denise Bottmann. 1. ed. São Paulo: Companhia das Letras, 2013.

\section{CREDENCIAIS DO AUTOR}

Sheryl Sandberg é atualmente diretora de operações do Facebook. Sandberg estudou economia na Universidade de Harvard, além de um mestrado em Administração pela Escola de Negócios, da mesma instituição. Também atuou como economista do Banco Mundial, na empresa de consultoria McKinsey \& Company e para o estado americano, no Departamento do Tesouro em Washington. Antes de ingressar no Facebookem 2008, Sandberg atuou na Google. Por conta de sua experiência e atuação em cargos de liderança, ao longo dos anos Sandberg foi acumulando uma série de conhecimentos, observações e experiências em torno da participação das mulheres nos negócios, o que a impulsionou a escrever Faça Acontecer: Mulheres, Trabalho e Vontade de Liderar (2013); o livro foi publicado em conjunto com o lançamento da Lean In, uma organização de educação e construção de comunidades para mulheres nos negócios.

\section{RESUMO}

Apesar da literatura científica apontar para as semelhanças entre os estilos e desempenho em cargos de liderança ocupados por homens ou mulheres (GIPSON et al, 2017), a discrepância na representatividade em cargos gerenciais por gênero ainda persiste nas organizações. São diversos os obstáculos (estereótipos, preconceitos, discriminação, entre outros) enfrentados por mulheres na busca de maior participação e representação em posições de lideranças na ciência, na política e nas organizações (SHVEDOVA, 2005; HOYT, 2010; DUNN; GERLACH; HYLE, 2014; HOWE-WALSH; TURNBULL, 2016; GIPSON et al, 2017; HRYNIEWICZ; VIANNA, 2018).

Tendo em vista o cenário apontado anteriormente, Faça Acontecer - Mulheres, Trabalho e a Vontade de Liderar de Sheryl Sandberg é uma obra que aporta velhas e novas discussões sobre o tema. O livro aparentemente é direcionado às mulheres, mas como a própria autora destaca, este é também dirigido aos homens (SANDBERG, 2013). Sandberg deixa claro o endereçamento de público do livro no seguinte trecho:

Estou escrevendo este livro, seja ele o que for, para todas as mulheres que queiram aumentar suas chances de chegar ao topo em seu campo ou queiram perseguir uma meta com empenho e dedicação. Isso inclui mulheres em todas as fases da vida e da carreira, desde as que estão apenas começando até aquelas que deram um tempo e talvez queiram voltar. Também estou escrevendo para todos os homens que queiram entender o que uma mulher - colega, esposa, mãe ou filha - está combatendo, e assim eles também possam dar sua contribuição para construir um mundo igualitário (SANDBERG, 2013, p. 23). 
Ainda no começo da obra, Sandberg esclarece a finalidade do livro:

Este livro não é um livro de memórias, embora eu tenha incluído histórias sobre minha vida. Não é um livro de autoajuda, embora eu realmente espere que ajude. Não é um livro sobre gestão de carreira, apesar de eu oferecer conselhos nessa área. Isto não é um manifesto feminista - ok, é uma espécie de manifesto feminista, mas um que eu espero que inspire os homens tanto quanto inspira as mulheres (SANDBERG, 2013, p. 23).

O prefácio da obra é de autoria da empresária brasileira Luiza Helena Trajano, que faz um apanhado dos desafios enfrentados pelas mulheres no contexto nacional e aponta algumas contribuições do livro de Sandberg para o debate sobre o tema.

O livro inicia pelo o que a autora denomina de "Internalizando a Revolução". Sandberg faz um chamamento para que as mulheres se unam e se apoiem no intuito de elevar o número de mulheres nas diferentes instâncias e em posições de liderança, deixando claro que não se trata de um manifesto feminista. Ao fazer tal chamamento, Sandberg também destaca o papel dos homens, dos parceiros dessas mulheres, os quais possuem um papel determinante no suporte para o alcance desse objetivo.

Sandberg lembra que no mundo corporativo há uma espécie de manual, onde as mulheres, para se "encaixarem" nas posições de liderança, são recomendadas a agir como homens e, quando estas tentam imitar o comportamento masculino, sendo por exemplo agressivas, sofrem críticas, represálias e outros obstáculos institucionais.

A autora aborda diversos temas que permeiam os desafios enfrentados pelas mulheres na construção de uma carreira, nos seguintes capítulos: 1.0 abismo nas ambições de liderança: $O$ que você faria se não tivesse medo? (p. 25); 2 . Um lugar à mesa (p. 43); 3. Sucesso e simpatia (p. 57); 4. É um trepa-trepa, não uma escada (p. 72); 5. Você é meu mentor? (p. 86); 6. Busque e diga a verdade como você a vê (p. 100); 7. Não saia antes de sair (p. 117); 8. Faça de seu companheiro um companheiro de verdade (p. 132); 9.0 mito de fazer tudo (p. 153); 10. Vamos começar a falar disso (p. 175); 11. Trabalhando juntos pela igualdade, (p. 197).

Sandberg apresenta maneiras de superar obstáculos internos e externos que podem atrapalhar o desenvolvimento de mulheres na carreira profissional. Ela descreve ações específicas que as mulheres podem tomar para combinar a realização profissional com a realização pessoal e demonstra como os homens podem se beneficiar apoiando mulheres no local de trabalho e em casa.

O livro trata, antes de tudo, de um chamamento para que as mulheres aspirem posições de liderança. Neste ponto, Sandberg aponta como ocorre o desenvolvimento e socialização de meninos e meninas ao longo da vida e como isso é determinante para as aspirações futuras de cada gênero.

Como bem destaca a autora, as barreiras impostas pela sociedade às mulheres, acabam sendo interiorizadas por meio de mensagens negativas que são ouvidas ao longo da vida. Para as mulheres existe uma grande decisão a ser tomada em algum momento da vida profissional: devo parar o progresso da carreira para cuidar dos filhos ou não? De fato, esta é uma grande questão. Numa sociedade machista não é nada comum um homem deixar a carreira de lado para cuidar dos filhos, este papel geralmente fica a cargo da mulher. Curioso notar um aspecto observado por Sandberg: além de sofrerem preconceito e resistências do público masculino, as mulheres também sofrem resistência por parte de outras mulheres, quando ascendem a posições de liderança.

Sandberg chama a atenção para dois aspectos relevantes. Primeiro, apesar dos avanços na redução das diferenças entre homens e mulheres no ambiente organizacional, as mulheres hesitam em dar grandes passos, seja por medo do fracasso, ou por contrariarem as normas, além de internalizarem os estereótipos negativos e os paradigmas de uma sociedade predominantemente machista. Há de se destacar como tais aspectos dialogam com alguns fenômenos organizacionais, que se apresentam como barreiras às mulheres, 
como o "teto de vidro" "(VAZ, 2013), "pisos pegajosos 2" (FERNANDEZ, 2019), "síndrome do impostor" (MATOS, 2014) entre outros.

O livro aborda uma questão central que permeia muitas das discussões sobre as mulheres no mercado de trabalho: como ter um trabalho significativo e adequadamente remunerado e, paralelamente uma vida pessoal satisfatória. E o livro faz uma indagação geral: como passar a mensagem e influenciar as futuras gerações de mulheres para que tomem o seu lugar à mesa?

Há três mensagens centrais no livro: 1 . Sente-se à mesa: Sandberg observa que os homens estão sempre buscando oportunidades e colocando-se à frente com muito mais frequência que as mulheres; 2 . Não saia antes de sair: Sandberg reconhece que as mulheres muitas vezes enfrentam escolhas mais difíceis entre sucesso profissional e realização pessoal do que seus colegas do sexo masculino. No entanto, muitas vezes as mulheres deixam a força de trabalho prematuramente para buscar o planejamento familiar, o que pode levar perda de oportunidades de trabalho e; 3 . Faça do seu parceiro um verdadeiro parceiro: a autora ressalta que as mulheres fazem mais progressos no trabalho buscando equilíbrio na relação com seus parceiros.

\section{APRECIAÇÃO CRÍTICA DO RESENHISTA}

Entre os pontos positivos da obra podemos destacar os relatos pessoais da autora referentes aos episódios de assédio, opressão, entre outros vividos pela própria, que demonstram que não importa a posição que uma mulher ocupe dentro de uma organização, os problemas gerados pelas diferenças de gênero se fazem presentes. Outro aspecto positivo do livro é a apropriação de diversos estudos científicos e análises de profissionais no qual o livro está respaldado. Ao tratar dos diversos temas que apresenta, Sandberg tem uma clara preocupação (talvez consequência de sua formação acadêmica) de oferecer evidências, principalmente científicas, dos problemas que são apresentados. Assim, o estilo do livro, que é caracterizado por uma conversação, acaba sendo embasado em diversos momentos por dados concretos e evidências de pesquisas para apoiar os argumentos.

Por outro lado, há pontos controversos que fragilizam o livro. Primeiro, a tese do livro é que se as mulheres fossem mais ambiciosas, talvez teríamos mais mulheres líderes, ou seja, a autora transfere parte do problema para as mulheres, deixando em segundo plano as discussões sobre mudanças estruturais necessárias para alterar o cenário explicitado. Segundo, apesar de ressaltar o ambiente machista, o livro atribui certa culpa e responsabilização da falta de mulheres líderes às próprias mulheres. Nesse aspecto, importante considerar que os esforços das organizações, no sentido de promover um ambiente de igualdade de oportunidades, são tão importantes quanto os próprios esforços das mulheres para buscar reduzir as diferenças.

Curiosamente, Sandberg não relata ao longo do livro problemas quanto aos afazeres domésticos, apenas de forma pontual e principalmente ao tratar do período no qual esteve grávida, algo que distancia a obra da realidade de muitas das mulheres no Brasil, que lidam com uma dupla jornada de trabalho. Segundo o Instituto Brasileiro de Geografia e Estatística (IBGE, 2018), as mulheres brasileiras dedicam em média 18,1 horas semanais para tarefas domésticas, enquanto os homens dedicam cerca de 10,5 horas. Também devemos lembrar que o ponto de partida de Sandberg é o núcleo familiar tradicional, com pai, mãe e filhos, todavia, atualmente observamos novas configurações familiares na sociedade e um crescimento de mães solteiras e chefe de família no Brasil, por exemplo (CAVENAGHI; ALVES, 2018).

Podemos notar que se trata de um livro escrito por uma mulher singular: da classe média, que posteriormente ingressou na classe alta, que estudou em uma das melhores universidades do mundo

\footnotetext{
1 "Teto de vidro" caracteriza-se pela menor velocidade com que as mulheres ascendem na carreira, o que resulta em sua sub-representação nos cargos de comando das organizações e, consequentemente, nas altas esferas do poder, do prestígio e das remunerações (VAZ, 2013, p. 765-766).

2 "Piso pegajoso" refere justamente a dificuldade que as mulheres concentradas nestes setores e empregos menos valorizados economicamente encontram para alterar a sua situação (FERNANDEZ, 2019, p. 89).

3 "Síndrome do impostor" está associada às pessoas que não acreditam que são inteligentes, que veem suas capacidades como superestimadas, mesmo que isto não seja verdadeiro, além de atribuírem suas realizações à sorte ou ao esforço adicional empregado na realização de tarefas (MATOS, 2014).
} 
(Universidade de Harvard), que trabalhou em grandes organizações, com muitas oportunidades (o que não constitui a realidade da grande maioria das mulheres no mercado de trabalho) e que ao longo de sua carreira observou cenas de discriminação por questões de gênero. É um livro que fala que a mulher, em condições semelhantes, pode alçar uma posição de liderança ou, na melhor das hipóteses, pode servir para inspirar outras mulheres.

Sheryl Sandberg trabalhou no Banco Mundial, no Governo dos Estados Unidos como chefe de gabinete do secretário do Tesouro Americano, na Consultoria McKinsey \& Company, no Google até chegar ao Facebook em 2008, onde atualmente é Diretora de Operações. Não é à toa que Sandberg é considerada uma das 100 mulheres mais influentes e poderosas do mundo (FORBES, 2019a), além de fazer parte do seleto time de bilionários globais, com uma fortuna estimada em 1,6 bilhões de dólares (FORBES, 2019b).

Cabe resgatar aqui a participação da autora no TED Talks 2010, com uma palestra intitulada "Por que temos tão poucas líderes"? ${ }^{4}$ Ousamos aqui responder: talvez seja por termos tão poucas mulheres com as mesmas condições de Sheryl Sandberg.

O livro, trazendo-o para a realidade brasileira, talvez não contemple a nossa diversidade, contudo, aborda um problema que é comum: a diferença de gênero e suas repercussões no mercado de trabalho. No Brasil em 2016, 39,1\% dos cargos gerenciais eram ocupados por mulheres, que em geral, recebem remuneração menor que os homens (IBGE, 2018).

Sandberg aborda as diferenças no que concerne ao gênero no meio organizacional, no olhar de uma pessoa branca. A autora não aborda outro grave problema: o racismo. Isto é, mulheres que além de serem discriminadas por serem mulheres, sofrem por não serem brancas. Mas, devemos lembrar que o livro fala do ambiente e história da autora, não sendo seu objetivo fazer um amplo apanhado sobre as questões de diversidade organizacional.

Curioso notar que Sandberg aborda muito o papel do mentor, daquele ou daquela que, com sua experiência e expertise, colabora para a carreira profissional de outra pessoa. No seu caso, é importante frisar que ao longo da carreira da referida autora, seus mentores foram homens, como a própria destaca. Exceto para a elaboração deste livro, onde a autora ressalta a mentoria de Gloria Steinem e Arianna Huffington.

A mensagem de Sandberg também não é nova, talvez o "lugar de fala" seja novo: uma importante líder, com grande influência, falando sobre as dificuldades de se alcançar posições de liderança em contextos dominados por homens.

Mesmo com todos os recursos que possui, Sandberg experimentou inseguranças que, talvez, boa parte das mulheres possuam e isso acaba gerando uma empatia entre o livro e o público, visto que, não são análises feitas por um terceiro, mas pelo sujeito que os vivenciou.

$\mathrm{Na}$ literatura, geralmente temos livros sobre desigualdade de gênero que estão focados no que precisa ocorrer social, cultural e/ou institucionalmente, para mudar esse quadro. O livro de Sandberg aborda essa discussão, sob o ponto de vista do que as mulheres precisam fazer para enfrentar as barreiras existentes.

Por fim, apesar das limitações da obra, geradas em boa parte pelo tipo de experiência que a autora teve em sua carreira, não retiram da mesma a qualidade da escrita e das contribuições que esta apresenta para o tema do gênero e liderança no contexto organizacional. A leitura do livro é recomendável, não apenas pelas inúmeras discussões e temas paralelos à questão de gênero no mercado de trabalho, mas por dar continuidade a um diálogo necessário entre homens e mulheres no meio organizacional.

A narrativa apresentada por Sandberg também pode ser útil aos profissionais que se dedicam às finanças comportamentais, principalmente àqueles que atuam com o público feminino, por exemplo. Da mesma forma, o livro é interessante para profissionais de coaching que atuam na orientação de carreiras, especialmente as de mulheres, além de um guia para gestores de pessoas, que podem obter insights a partir das experiências relatadas no livro. Há também de se apontar, a utilidade do livro para mulheres que atuam em posições gerenciais nas organizações e que podem se beneficiar as discussões apresentadas no livro, para mudar ou aprimorar práticas de gestão.

\footnotetext{
${ }^{4}$ A palestra está disponível em: https://www.ted.com/talks/sheryl_sandberg_why_we_have_too_few_women_leaders?language=pt-br. Acesso em: 14 dez. 2019.
} 
A obra também pode servir de referência para a elaboração de programas e políticas direcionadas a equilibrar as disparidades de gênero no contexto organizacional. As discussões podem ser relevantes para pesquisadores e interessados no tema do gênero e trabalho/carreira, pois apresenta a trajetória de uma líder e diversas temáticas paralelas às questões de gênero.

\section{REFERÊNCIAS}

CAVENAGHI, Suzana; ALVES, José Eustáquio D. Mulheres chefes de família no Brasil: avanços e desafios. Rio de Janeiro: ENS-CPES, v. 120, 2018. Disponível em: http://www.ens.edu.br/arquivos/mulheres-chefes-defamilia-no-brasil-estudo-sobre-seguro-edicao-32 1.pdf. Acesso em: 11 jan. 2020.

DUNN, Dana; GERLACH, Jeanne M.; HYLE, Adrienne E. Gender and leadership: Reflections of women in higher education administration. International Journal of Leadership and Change, v. 2, n. 1, p. 2, 2014. Disponível em: https://digitalcommons.wku.edu/ijlc/vol2/iss1/2/. Acesso em: 13 jan. 2020.

FERNANDEZ, Brena Paula Magno. Teto de vidro, piso pegajoso e desigualdade de gênero no mercado de trabalho brasileiro à luz da economia feminista: por que as iniquidades persistem? Cadernos de Campo: Revista de Ciências Sociais, n. 26, p. 79-104, 2019. Disponível em: https://periodicos.fclar.unesp.br/cadernos/article/view/12951. Acesso em: 14 jan. 2020.

FORBES. Billionaires: The Richest People In The World. 2019b. Disponível em: https://www.forbes.com/billionaires/\#68003877251c. Acesso em: 13 jan. 2020.

The World's 100 Most Powerful Women. 2019a. Disponível em: https://www.forbes.com/powerwomen/\#1da038385e25. Acesso em: 10 jan. 2020.

GIPSON, Asha N. et al. Women and leadership: Selection, development, leadership style, and performance. The Journal of Applied Behavioral Science, v. 53, n. 1, p. 32-65, 2017. Disponível em: https://journals.sagepub.com/doi/10.1177/0021886316687247. Acesso em: 16 jan. 2020.

HOWE-WALSH, Liza; TURNBULL, Sarah. Barriers to women leaders in academia: tales from science and technology. Studies in Higher Education, v. 41, n. 3, p. 415-428, 2016. Disponível em:

https://www.tandfonline.com/doi/abs/10.1080/03075079.2014.929102. Acesso em: 19 jan. 2020.

HOYT, Crystal L. Women, men, and leadership: Exploring the gender gap at the top. Social and Personality Psychology Compass, v. 4, n. 7, p. 484-498, 2010. Disponível em: https://onlinelibrary.wiley.com/doi/abs/10.1111/j.1751-9004.2010.00274.x. Acesso em: 14 jan. 2020.

HRYNIEWICZ, Lygia Gonçalves Costa; VIANNA, Maria Amorim. Mulheres em posição de liderança: obstáculos e expectativas de gênero em cargos gerenciais. Cadernos EBAPE. BR, v. 16, n. 3, p. 331-344, 2018. Disponível em: http://www.scielo.br/pdf/cebape/v16n3/1679-3951-cebape-16-03-331.pdf. Acesso em: 11 jan. 2020.

IBGE. Estatísticas de Gênero - Indicadores sociais das mulheres no Brasil. Estudos e Pesquisas - Informação Demográfica e Socioeconômica, n. 38, 2018. Disponível em: https://biblioteca.ibge.gov.br/visualizacao/livros/liv101551 informativo.pdf. Acesso em: 18 jan. 2020.

MATOS, Patricia Andréa Victorio Camargo de. Síndrome do impostor e auto-eficácia de minorias sociais: alunos de contabilidade e administração. 2014. 91f. Dissertação (Mestrado em Controladoria e Contabilidade) -Departamento de Contabilidade e Atuária, Universidade de São Paulo, São Paulo, 2014.

SANDBERG, Sheryl Faça acontecer: mulheres, trabalho e a vontade de liderar. Tradução Denise Bottmann. 1. ed. São Paulo: Companhia das Letras, 2013.

SHVEDOVA, Nadezhda. Obstacles to women's participation in parliament. Women in parliament: Beyond numbers, v. 33, p. 22-45, 2005. Disponível em: https://www.idea.int/sites/default/files/publications/womenin-parliament-beyond-numbers-a-revised-edition.pdf. Acesso em: 14 jan. 2020. 
VAZ, Daniela Verzola. O teto de vidro nas organizações públicas: evidências para o Brasil. Economia e Sociedade, v. 22, n. 3, p. 765-790, 2013. Disponível em: http://www.scielo.br/pdf/ecos/v22n3/07.pdf. Acesso em: 11 jan. 2020. 